\title{
Considerations on lung cancer management reengineering
}

\begin{abstract}
Objective: The main objective of this study is to perform a situation diagnosis of the actual care route for intra and interlevel diagnosis and treatment of lung cancer through the opinion of experts linked to its performance, with the aim to identify the critical areas which may have repercussion on the economic sustainability of the care model and on patient's outcomes.
\end{abstract}

Materials and methods: For this purpose it has been developed a questionnaire linked to principles of business organization (Dialogical Practices and Relational Coordination) to explore organizational factors and possibilities for collaborative construction of healthcare superstructures.

Results: The lack of organizational integration/reconfiguration mediated by the low adherence to organizational factors related to Relational Coordination and Dialogical Practices explains recurrence in inefficient inter-level circuits that causes losses of value in the assistance and in the knowledge transmission flows.

Conclusions: Throughout the research, a high variability has been observed in relation to the percentage of consensus obtained for each one of the raised items. This indicates that the organizational factors related to Relational Coordination and Dialogical Practices models have a medium degree of implementation and for some issues this degree decreases. All of this leads to a reflection about the need to reconfigure current care processes to accommodate them to a real continuity of care and to a managed efficiency.

Keywords: relational coordination, dialogic practices, lung cancer, dynamic capabilities, triple aim, lean management
Volume 7 Issue $3-2017$

\author{
José Antonio Vinagre-Romero,' Carmen de- \\ Pablos-Heredero ${ }^{2}$ \\ 'PhD in Business Organization, El Escorial University Hospital, \\ Spain \\ ${ }^{2} \mathrm{PhD}$ in Economics, School of Social Sciences, Universidad Rey \\ Juan Carlos, Spain
}

Correspondence: José Antonio Vinagre-Romero, PhD in Business Organization, Quality Management and Health Information Systems, El Escorial University Hospital, Spain, Email: joseantonio.vinagre@salud.madrid.org

Received: September 27, 2017| Published: October 06, 2017

\section{Introduction}

From the health perspective, lung cancer represents a critical health concern with high rates of incidence and mortality and incurred incremental costs for care that pose a serious burden on health systems. ${ }^{1,2}$ From the social perspective, it causes productivity losses and other intangible costs that increases significantly its consideration as a public health problem. The social perspective needs to be addressed from new models of disease management. ${ }^{3,4}$

Examining the trends of increase in health expenditure and its relation with survival increase, ${ }^{5}$ we find that there are potential inefficiencies in the design of care processes related to patient navigation between health levels. These inefficiencies are based on coordination aspects such as inefficient knowledge transfer, inappropriate communication, lack of agreed protocols, etc. From this perspective, there is a need to rethink the organizational architecture of complex processes such as lung cancer. The redesigning should shorten diagnosis and treatment times, reduce transaction costs incurred by patients' inter-level navigation, generate a decrease in costs for hospital stays, promote a reduction in the productivity losses of individuals, etc.

In order to address a process of deep restructuring of the care process, this paper proposes as a methodological basis, the integration of organizational factors specific to health organizations with Dialogic Practices ${ }^{6}$ and the Relational Coordination model ${ }^{7}$ in order to identify those observable and latent variables that may be conditioning the effectiveness of organizational routines between the two levels of care for the pathology of interest.
The main objective of this study is, therefore, to perform a situation diagnosis of the current care route for intra and interlevel diagnosis and treatment of lung cancer through the opinion of experts linked to its performance, with the aim to identify the critical areas which may impact on the economic sustainability of the care model and on patients' outcomes.

\section{Materials and methods}

The study was designed based on a Delphi methodology. This method is applied with a prospective intention in order to gather information from a group of experts about a certain problem that arises for their discussion. Its application in health sciences allows a consensus methodology to deal with highly complex issues that requires the participation of heterogeneous and numerous groups, and which may be characterized by a high variability component in clinical practice. ${ }^{8}$

To do this, an initial questionnaire was prepared for the first round in December 2017, including 16 questions (Tables 1A-C) each one referring to a different theoretical approach. Six of them explored organizational factors compared to the communication dimension of the Relational Coordination model, three questions linked these organizational factors with the relational dimension of the same model, four questions explored the organizational interrelations with the Dialogic Practices and two final questions that inquired about reputation related to the internal and external organizational structure respectively. All of these questions were open-ended and did not have an extension limit. 
Next, a panel of experts with professional profiles linked to Specialized Care (SC) and Primary Care (PC), as well as to academic and biomedical research institutions, was contacted during the second half of January 2017 (Tables 1A-C).

Once the responses of the first-round questionnaire were received along the first half of February 2017, a descriptive analysis of the responses provided and assimilation to closed categories were

Table IA Delphi questionnaire round I performed in order to facilitate analysis and interpretation of results (Figure1). Considering the answers, a SWOT matrix was built with the main ideas highlighted by the experts Figure 2 in the second half of February 2017. Finally, the matrix was sent in a second round to collect experts' opinion with a unique open-ended question in the first half of March 2017, to show agreement/disagreement on the statements proposed in the matrix Figure 3.

Questions Organizatonal factor
QI: In a problem such as lung cancer, which
requires a multiprofessional and multicentric Inter-level Repeated
approach, do you think that communication Interaction
among professionals at both levels of care is a
critical factor?

Q2: How do you think "frequency of communication" between levels should be, and what factors can influence it?

Inter-level Repeated Interaction

Q3: From your point of view, do you think there is room for improvement to make communication in shorter time frames for the patient's benefit?

Patient-centered
Communication

Q4: Do you consider that communication is focused on streamlining patient's clinical process or, on the contrary, it focuses on other aspects such as normative or administrative questions?

Q5:When clinical information exchanging is carried out among professionals involved in patient's diagnosis and treatment, is this information sufficiently detailed to have an overall understanding of the case and to promote continuity of care?

Q6:Although the clinical course of the disease follows predictable pathophysiological patterns, sometimes there are complications or adverse events which may cause a torpid evolution and potential conflicts. In these cases, do you think that professionals know how to redirect the casuistry to the appropriate clinical resource at the right level and at the right time in a consensual way?

Q7: Do you consider that intra (PC or EC) or interlevel (PC-EC-PC) professional teams are

focused on getting the best results in patients Patients Outcomes or somehow deviate from that purpose to focus on achieving required performance indicators?

Q8: In your opinion, how would you value accessibility to clinical information to provide a personalized and continued treatment to the patient depending on the level where this information is hosted PC or EC? Is this accessibility bidirectional?

Referral to Specific Resources and Conflict Management

Patient-centered Communication

Detailed Information

\section{RC Model}

dimension correspondence

RC Model
Sub-dimension
correspondence

Dimensions

Assessed in larger

workgroups correspondenc ${ }^{9}$

Communication (General)

Communication

Frequent

Communication

Communication

Timely

Communication

Communication

Relational

Timely

Coordination

Communication

Communication

Dimensions

Accurate

Communication

Coordination (Mutual Adjustment)

\section{Problem-Solving Active Conflict \\ Communication Management}

Relational
Coordination
Relational

Dimensions
Shared Decision

Shared Knowledge Making

Collaboration
Q9: Do you believe that there are intra or interlevel organizational behaviors that promote recognition of clinical care performed by the different professionals involved in the process?
Inter-level Professional Recognition

\section{Medical Inter-level \\ Records Sharing}

(a)

Source: Own development, 2017 on Gittell's ${ }^{7}$ and Valentine's ${ }^{9}$ 
Table IB Delphi questionnaire round I

\begin{tabular}{|c|c|c|c|}
\hline Questions & $\begin{array}{l}\text { Organizational } \\
\text { Factor }\end{array}$ & $\begin{array}{l}\text { DP Dimension } \\
\text { correspondence }\end{array}$ & $\begin{array}{l}\text { Dimensions assessed } \\
\text { in larger workgroups } \\
\text { correspondence }^{9}\end{array}$ \\
\hline $\begin{array}{l}\text { Q I0: Do you consider that clinical care provided to patients } \\
\text { is always based on the best available scientific evidence or on } \\
\text { organizational routines? }\end{array}$ & $\begin{array}{l}\text { Evidence-based } \\
\text { practices }\end{array}$ & $\begin{array}{l}\text { Epistemic } \\
\text { Contestation }\end{array}$ & Effort \\
\hline $\begin{array}{l}\text { QI I: Do you consider adequate joint clinical sessions (PC-EC) for } \\
\text { interdisciplinary and personalized approach of patients' clinical } \\
\text { cases? If they are structured in your organization, do you consider } \\
\text { them to be agile, frequent and resolute? }\end{array}$ & $\begin{array}{l}\text { Clinical Cases } \\
\text { Discussion }\end{array}$ & Joint Sensemaking & $\begin{array}{l}\text { Use of All Contributors' } \\
\text { Expertise } \\
\text { Shared Decision Making } \\
\text { Collaboration }\end{array}$ \\
\hline $\begin{array}{l}\text { QI2:According to your knowledge and in reference to lung cancer, } \\
\text { are there consensual clinical pathways between levels (PC-EC) for } \\
\text { diagnosis and treatment? Do you think that these would result in } \\
\text { a more effective coordination and control of costs of transaction, } \\
\text { opportunity and those derived from the progression of the } \\
\text { disease? }\end{array}$ & Clinical Pathways & $\begin{array}{l}\text { Cross-boundary } \\
\text { Intervention }\end{array}$ & $\begin{array}{l}\text { Effort } \\
\text { Coordination (Mutual } \\
\text { Adjustment) }\end{array}$ \\
\hline \multicolumn{4}{|c|}{$\begin{array}{l}\text { Q/3:As in the previous question, are you aware of the existence of } \\
\text { protocols of action that allow the immediate derivation between } \\
\text { levels without following the established administrative processes in Emergency SituationsProtocol Breaking } \\
\text { case of emergency related to the health status of the patient and } \\
\text { for the pathology of study? }\end{array}$} \\
\hline
\end{tabular}

Source: Own development, 2017 on Faraj et al. ${ }^{6}$ and Valentine's ${ }^{9}$

Table IC Delphi questionnaire round I

\begin{tabular}{|c|c|c|c|}
\hline Questions & $\begin{array}{l}\text { Organizational } \\
\text { factor }\end{array}$ & $\begin{array}{l}\text { Exogenous } \\
\text { correspondence }\end{array}$ & $\begin{array}{l}\text { Dimensions assessed } \\
\text { in larger workgroups } \\
\text { correspondenc }\end{array}$ \\
\hline $\begin{array}{l}\text { Q/4: Do you think that greater knowledge of the organization } \\
\text { itself favors coordination and results in patients? In what way } \\
\text { do you think it does it? }\end{array}$ & $\begin{array}{l}\text { Intra-level } \\
\text { Coordination }\end{array}$ & $\begin{array}{l}\text { Internal Organizational } \\
\text { Structure }\end{array}$ & $\begin{array}{l}\text { Coordination (Mutual } \\
\text { Adjustment) }\end{array}$ \\
\hline $\begin{array}{l}\text { Q I5: Related to the previous question, do you consider that } \\
\text { greater organizational knowledge between both levels of care } \\
\text { would favor coordination and the final results in patients? In } \\
\text { what way do you think it would do it? }\end{array}$ & $\begin{array}{l}\text { Inter-level } \\
\text { Coordination }\end{array}$ & $\begin{array}{l}\text { External Organizational } \\
\text { Structure }\end{array}$ & $\begin{array}{l}\text { Coordination (Mutual } \\
\text { Adjustment) }\end{array}$ \\
\hline
\end{tabular}

Source: Own development, 2017 on Valentine's $s^{9}$

\section{Results}

A total of 28 experts were contacted in the first round. One declined his participation for personal reasons. In 5 cases there was no confirmation, and 22 agreed to participate. Finally, 17 completed questionnaires were received.

Next, considerations made by experts regarding the questionnaire raised in the first round are exposed with narrative criteria as it follows, although in Figure 1, an assimilation of the open answers provided by experts in closed categories is made to facilitate the evaluation of the organizational state:

i. Q1: According to experts surveyed with a total degree of unanimity, communication in complex processes was critical in disease prevention, symptom-diagnosis, diagnosis-active treatment and active treatment-palliative care intervals. It was also decisive at intra-hospital and inter-level relationships, coordinating a structured response PC-Emergency Department (ED)-SC to shorten waiting times and prevent complications.

ii. Q2: On this issue, there was a majority agreement on the desira- bility that communication should be a flexible mechanism, with well-identified partners, and it should be established according to patient-related needs. On the other hand, other respondents answered that this should be continuous and even formally programmed with a minimum periodicity.

iii. Q3: There was again a remarkably high degree of consensus on this issue. One of the key points of the opinions expressed was about the need to promote the immediacy of communication through IT tools. The convenience of providing a unique clinical record that would greatly shorten response times among professionals was emphasized as it would keep clinical records permanently updated providing personalized follow-up, and it would not interfere with direct care times at the same time that would also promote patient safety, etc.

iv. Q4: Considering this question, a large degree of variability in the responses provided is evident. While it was well established that the core of communication should be patient-centered, it was argued that there is a dominant component of bureaucratization. This professional bureaucratization could be rooted in the strong nor- 
malization that characterizes any care process, which, on a fully guarantor basis, pursues the documentary assurance of each clinical act.

v. Q5: Again, for the case of this question, a quite dispersed response grouping appeared. Eight of the experts surveyed considered that the information accessed was sufficiently detailed for cases monitoring using platforms such as HORUS or hospital clinical stations (accessible to PC). In another response group, it was considered that the level of detail of clinical information was improvable. In the last grouping for this question, it was argued that this information was not sufficiently detailed or inappropriate for the assurance of inter-level continuity of care. (Figure 1)

vi. Q6: Regarding the pertinence of referral to the right resources at the right level in case of complications or adverse events, most responses pointed to a low pertinence and great variability of the referral criteria used. In this group of answers that met the usual practice of referral to hospital ED, factors such as the lack of knowledge of the specific hospital processes and/or specific referral protocols, organizational barriers that motivate the withdrawal of referral to the most appropriate resources, the difficulty of management by PC practitioners of cancer-affected patients undergoing very novel treatments (including clinical trials) which was aggravated by work overload placed at this level, were considered. The rest of the opinions referred to a generally correct procedure supported by IT tools available for the two levels and by proceedings of application in case of objective complications.

vii. Q7: The case of this question generated a remarkable disaggregation in answers' grouping. For six of the experts, intra and inter-level teams' performance were focused on patient outcomes. In the opinion of five surveyed experts, health care teams' performance was closely linked to performance indicators achievement more than to the optimization (evidence-based) of patients' outcomes. Two of the shared experiences inferred a logical consequence between the achievement of patients' outcomes and the achievement of performance indicators and the four remaining collaborators did not manifest themselves specifically in any sense.

viii. Q8: As stated in Q8, thirteen responses pointed out that accessibility to information was limited/partial and non-bidirectional with issues that affected both levels of care related to the complementary. Also, in most cases, respondents did not appreciate a bi directionality in the generation of information, but it was exposed in a unidirectional way from one level to another as it is generated.

ix. Q9: Regarding this question, there was remarkable dispersion in the answers given being minority those that were expressed positively in terms of intra and inter-level acknowledgement. The existence of intra-level partial acknowledgements, as well as the anecdotic existence of multi-level recognition for the case of palliative care units, was also stated. Work overload and demotivation were mentioned as causes of the lack of recognition.

x. Q10: Again, a lack of consensus was shown on this issue. The answers that gave predominance to scientific evidence focused their statements on specific services and committees allocated in $\mathrm{SC}$, although they did not consider the evidence in the complementary level of PC regarding the targeted pathology. However, most of responses were oriented towards the coexistence of evidence and organizational routines. xi. Q11: In this case, there was a major positioning towards the convenience of the existence of PC-SC joint clinical sessions. The appraisals made by the experts were conclusive in the sense of pertinence in the development of these sessions, although the testimonial nature of these joint sessions was emphasized. The formative value that joint sessions was also highlighted. They would contribute as well to the optimization of accessibility and resource management.

xii. Q12: For this question, most responses pointed the non-existence of joint clinical pathways (PC-SC). There were great similarities at the time of positioning this clinical management tool at SC level, while at the PC level there would only be recommendations from scientific societies and referral protocols in case of diagnostic suspicion. Collaborators highlighted the potential improvements that this type of collaborative strategies would contribute to resource management avoiding tasks duplications which will cause costs of overproduction, waiting times that negatively influence the progression of the disease, opportunity costs incurred by organizational redundancies, transaction costs due to non-specific referral, etc.

xiii. Q13: The objective of this question was to investigate the knowledge of the actors at both levels (PC-SC) of the Lung Cancer Consultation Units that are available in some hospitals, as well as to evaluate the existence of coordinated protocols within the scope of the ED's with these specific units. Because of the above considerations, it was established that only two of the experts have identified resources specifically designed for the management of this pathology. Emergency care established different options that could be considered as non-specific such as referral from PC to ED with a PC practitioner report, referral from PC to SC for hospital admission through contacts with Continuity of Care Directors, via inter-level coordination units, inter-consultation parts between levels and intra-level specialties, etc.

xiv. Q14: This item shows a major degree of consensus regarding the improvement of patients' outcomes through a greater coordination acquired as a result of a greater knowledge of the organization itself. A series of areas of potential improvement were mentioned through intra-organizational knowledge as: Referral to specific resources eliminating redundant processes, waiting times shortening, , increased patient safety and decreased workloads by efficient organizational routines at meso and micro levels.

xv. Q15: As in the above question, there was a broad level of consensus regarding the positive contribution that greater knowledge between levels of the organization would bring in terms of outcomes in patients and for the system itself. Regarding the potential improvements to be achieved based on the implementation of this organizational factor, there were those mentioned for the previous question, and some that appeared in this section but which are fully complementary to the previous ones. In this sense reference was made to: Decreased stressors in patients and professionals, increased disease free survival, decreased sequelae, increased quality of life and increased system efficiency.

From the descriptive analysis of the answers in the first round, the following conclusions were synthesized in the form of a SWOT matrix (Figure 2).

In the second round, the same seventeen respondent experts were 
surveyed again. A SWOT matrix was sent to express agreement/ disagreement about the statements and grouping made from round 1 questionnaire (Figure 3). A total of eleven answered questionnaires were obtained. Next, considerations made by experts regarding the questionnaire raised in the second round are exposed with narrative criteria as it follows: Three of the experts surveyed suggested changes in the SWOT array. Two of the opinions expressed their dissent with the labeling of "work overload caused by increasing demand" and "incidence and prevalence of lung cancer" as threats. In this sense, it was argued that these two factors should be grouped within the opportunities because they represented a future challenge.

Another of the above considerations referred to the classification of "communication frequently linked to interpersonal ties" as weakness. To this respect, it was exposed that this situation was conditioned by the lack of method and formalization of the organizational communication processes. With respect to the heading "health professionals with very rigorous training" the proposal of modification suggested the change of "rigorous" by "exhaustive". The last of the observations made suggested the incorporation of a new option such as "free choice", which could be classified both as an opportunity and as a threat.

\begin{tabular}{|c|c|c|c|}
\hline QUESTIONS & $\begin{array}{l}\text { ORGANIZATONAL } \\
\text { FACTOR }\end{array}$ & ANSWERS & CONSENSUS \\
\hline 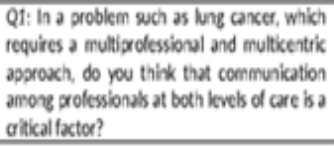 & $\begin{array}{l}\text { Interlevel Repeated } \\
\text { Interaction }\end{array}$ & $\begin{array}{l}\text { - } \quad \text { Yes: } 17 \\
\text { - } \quad \text { No:0 }\end{array}$ & $100 \%$ \\
\hline $\begin{array}{l}\text { Q2: How do you think "frequency of } \\
\text { communication" between levels should be, } \\
\text { and what batars can infuence it? }\end{array}$ & $\begin{array}{l}\text { Interilevel Repeated } \\
\text { Interaction }\end{array}$ & $\begin{array}{l}\text { - Flexible, well } \\
\text { identified and } \\
\text { according to } \\
\text { evolution: } 10 \\
\text { - Continuous: } 4 \\
\text { - Programmed: } 3\end{array}$ & $58,82 \%$ \\
\hline $\begin{array}{l}\text { Q3: From your point of view, do you think } \\
\text { there is room foe improvement to make } \\
\text { communication h shouter time frames for the } \\
\text { potient's benefit? }\end{array}$ & $\begin{array}{l}\text { Patientcentered } \\
\text { Communication }\end{array}$ & $\begin{array}{l}\text { - Yes: } 15 \\
\text { - Yes, with details: } 1 \\
\text { - } \quad \text { No: } 1\end{array}$ & $88,23 \%$ \\
\hline $\begin{array}{l}\text { QA: Do you consider tivat communication is } \\
\text { focused on streamlining patient's clinical } \\
\text { pocess of, on the contrary, it focuses on other } \\
\text { aspects such as normative or administrative } \\
\text { questions? }\end{array}$ & $\begin{array}{l}\text { Patient-centered } \\
\text { Communication }\end{array}$ & $\begin{array}{l}\text { - Patient-centered: } 8 \\
\text { - Should be PC: } 1 \\
\text { - Administrative: } 5 \\
\text { - Both: } 3\end{array}$ & $47,05 \%$ \\
\hline 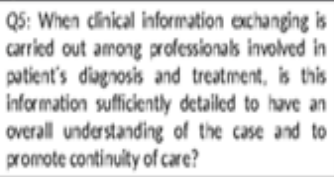 & Detailed information & $\begin{array}{l}\text { - Yes: } 8 \\
\text { - Improvable: } 4 \\
\text { - No:5 }\end{array}$ & $47,05 \%$ \\
\hline 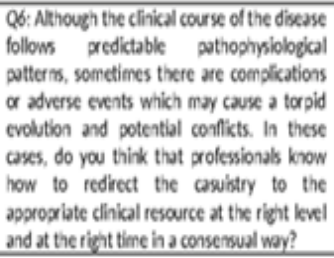 & $\begin{array}{l}\text { Referral to Specifix } \\
\text { Resources and } \\
\text { Conflict } \\
\text { Management }\end{array}$ & $\begin{array}{l}\text { Yes: } 7 \\
\text { Only to specific } \\
\text { resources } \\
\text { independently of } \\
\text { the deloy: } 1 \\
\text { - No: } 9\end{array}$ & $52.94 \%$ \\
\hline 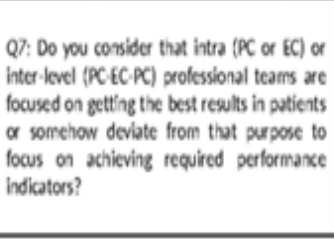 & Patients Outcomes & $\begin{array}{l}\text { - Patient-centered: } 6 \\
\text { - Performance- } \\
\text { centered: } 5 \\
\text { - Results in patients } \\
\text { linked to results in } \\
\text { performance: } 2 \\
\text { - Non-specific } \\
\text { answers: } 4\end{array}$ & $35,29 \%$ \\
\hline $\begin{array}{l}\text { Q8: In your opinion, how would you value } \\
\text { accessibility to dinical information to provide } \\
\text { a personalized and continued treatment to } \\
\text { the patient dexending on the level where this } \\
\text { information is hosted PC of EC? Is this } \\
\text { accessibility bidrectional? }\end{array}$ & $\begin{array}{l}\text { Nedical Inter-Level } \\
\text { Records Sharing }\end{array}$ & $\begin{array}{l}\text { - Good: } 4 \\
\text { - Uimited: } 13\end{array}$ & $76,47 \%$ \\
\hline 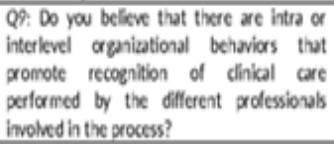 & $\begin{array}{l}\text { Interlevel } \\
\text { Professional } \\
\text { Recognition }\end{array}$ & $\begin{array}{ll}\text { - } & \text { Yes: } 5 \\
\text { - Partially: } 6 \\
\text {. No: } 6\end{array}$ & $35,29 \%$ \\
\hline $\begin{array}{l}\text { Q10. Do you consider that clinical care } \\
\text { provided to patients is always based on the } \\
\text { best avalable scientific evidence of on } \\
\text { organizational routines? }\end{array}$ & $\begin{array}{l}\text { Evidence-based } \\
\text { Practices }\end{array}$ & $\begin{array}{l}\text { - Scientific evidence: } \\
7 \\
\text { - Orzanizational } \\
\text { routines: } 2 \\
\text { - Both: } 8 \\
\end{array}$ & $47,05 \%$ \\
\hline
\end{tabular}

Source: Own development, 2017 


\begin{tabular}{|c|c|c|c|}
\hline QUESTIONS & $\begin{array}{l}\text { ORGANIZATIONAL } \\
\text { FACTOR }\end{array}$ & ANSWERS & CONSENSUS \\
\hline $\begin{array}{l}\text { Q11: Do you consider adequate joint } \\
\text { clinical sessions (PC.EC) for } \\
\text { interdisciplinary and personalized } \\
\text { appraxch of patients' clinical cases? if } \\
\text { they are structured in your } \\
\text { organization, do you consider them to } \\
\text { be agile, frequent and resolute? }\end{array}$ & $\begin{array}{l}\text { Cinical Cases } \\
\text { Discussion }\end{array}$ & $\begin{array}{ll}\text { - } & \text { Yes: } 12 \\
\text { - } & \text { No: } 3 \\
\text { - } & \text { Non-specific } \\
& \text { answers: } 3\end{array}$ & $70,58 \%$ \\
\hline $\begin{array}{l}\text { Q12: To your knowledge and about lung } \\
\text { cancer, are there consensual clinical } \\
\text { pathwass between levels (PC.EC) for } \\
\text { diagnosis and treatment? Do you think } \\
\text { that these would result in a more } \\
\text { effective coordination and control of } \\
\text { costs of transaction, opportunity and } \\
\text { those defived from the provession of } \\
\text { the disease? }\end{array}$ & Clinical Pathways & $\begin{array}{ll}\text { - } & \text { Yes: } 2 \\
\text { - No: } 13 \\
\text { - Under } \\
\text { development: } 1 \\
\text { - Non-specific } \\
\text { answers: } 1\end{array}$ & $76,47 \%$ \\
\hline $\begin{array}{l}\text { Q13: As in the previous question, are } \\
\text { you aware of the existence of protocols } \\
\text { of action that allow the immediate } \\
\text { derivation between levels without } \\
\text { following the established administrative } \\
\text { circuits in case of emergency related to } \\
\text { the health status of the potient and for } \\
\text { the pathology of study? }\end{array}$ & $\begin{array}{l}\text { Emergency } \\
\text { Situations }\end{array}$ & $\begin{array}{l}\text { - Pathologr-spectic: } \\
2 \\
\text { - Non-pathologr } \\
\text { specific: } 15\end{array}$ & $88,23 \%$ \\
\hline $\begin{array}{l}\text { Q14: Do you think that greater } \\
\text { knowledge of the organization itself } \\
\text { favors coordination and outcomes in } \\
\text { patients? In what way do you think it } \\
\text { does it? }\end{array}$ & $\begin{array}{l}\text { Intrarlevel } \\
\text { Coordinution }\end{array}$ & $\begin{array}{ll}\text { - } & \text { Yes: } 15 \\
\text { - } & \text { No: } 1 \\
\text { - } & \text { Non-specific } \\
& \text { answers: } 1\end{array}$ & $88,23 \%$ \\
\hline $\begin{array}{l}\text { Q15: Related to the previous question, } \\
\text { do you consider that greater } \\
\text { organizational knowledge between } \\
\text { both levels of care would favor } \\
\text { coordinution and final outcomes in } \\
\text { patients? In what way do you think it } \\
\text { would do it? }\end{array}$ & $\begin{array}{l}\text { Interlevel } \\
\text { Coordination }\end{array}$ & $\begin{array}{l}\text { - Yes: } 15 \\
\text { - No:1 } \\
\text { - Partially: } 1\end{array}$ & $88,23 \%$ \\
\hline
\end{tabular}

Figure I Delphi Panel of Experts' Answers at a Glance Round I.
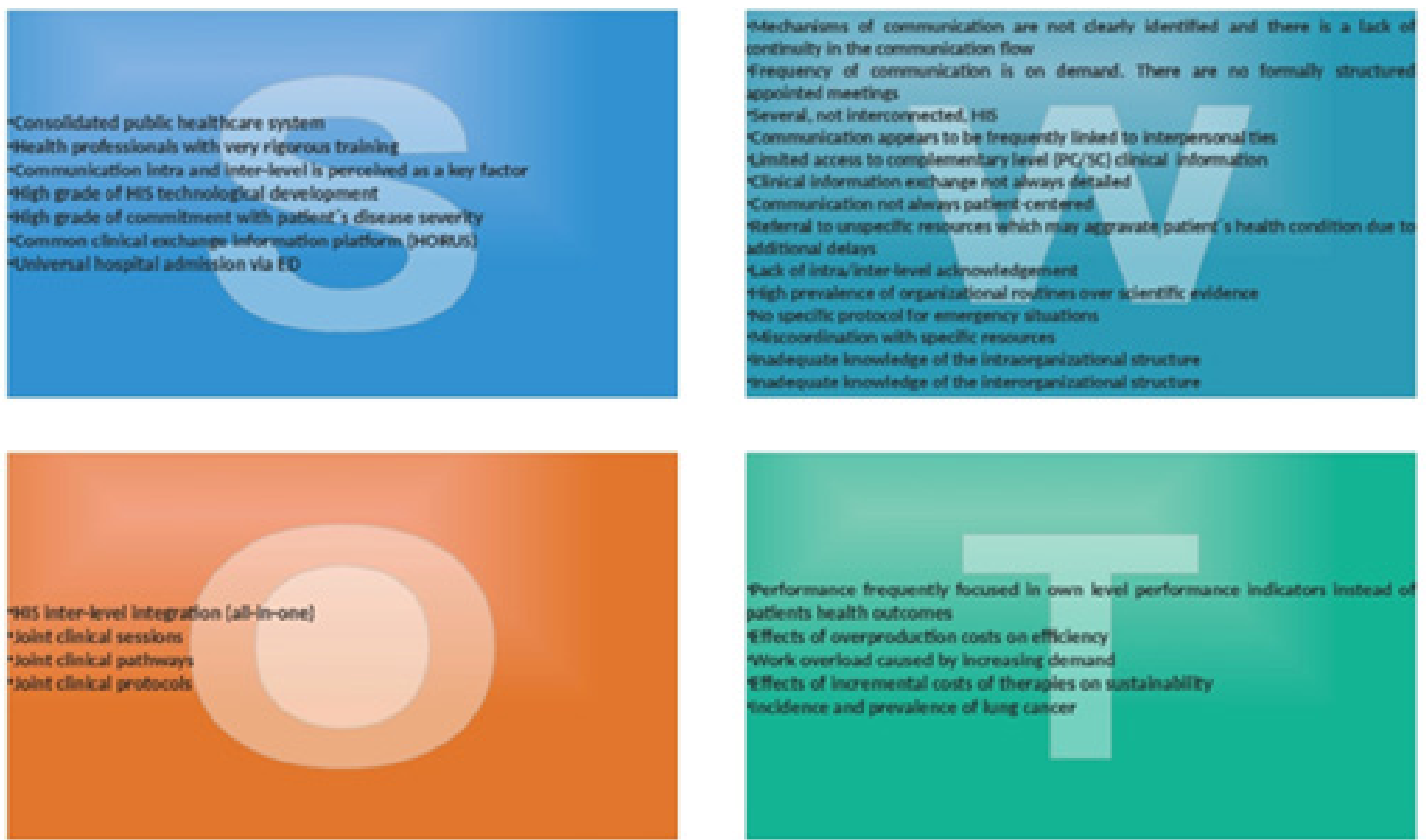

Sourte: Own development, 2017

Figure 2 SWOT Analysis from Delhi Questionnaire Round I.

Citation:Vinagre-Romero JA, Pablos-Heredero C. Considerations on lung cancer management reengineering. MOJ Clin Med Case Rep. 2017;7(3):249-256. DOI: 10.15406/mojcr.2017.07.00206 


\begin{tabular}{|c|c|c|c|}
\hline QUESTIONS & ANSWERS & POINTS OF DISACREEMENT & CONSENSUS \\
\hline $\begin{array}{l}\text { Q16: Do you agree with the conclusions } \\
\text { shown in the SWOT matrix? In case of } \\
\text { disagreement, please give your reasons. }\end{array}$ & $\begin{array}{l}\text { - Agree: } 8 \\
\text { - Disagree: } 3\end{array}$ & $\begin{array}{l}\text { - Tagsing of "work } \\
\text { overioad coused by } \\
\text { increasing demand" } \\
\text { as threat } \\
\text { - Tagsing of } \\
\text { "incidence and } \\
\text { prevalence of lung } \\
\text { cancer" as threat } \\
\text { Taesing } \\
\text { "communication } \\
\text { frequently linked to } \\
\text { interpersonal bes" } \\
\text { as weakness } \\
\text { In "health } \\
\text { professionals with } \\
\text { very rigorous } \\
\text { training", rigorous } \\
\text { should be replaced } \\
\text { for "ochaustive" to } \\
\text { better fit the } \\
\text { meaning of the } \\
\text { statement } \\
\text { Inclusion of "free } \\
\text { choice of hospital" } \\
\text { as both opportunity } \\
\text { and threat }\end{array}$ & $72,72 \%$ \\
\hline
\end{tabular}

Figure 3 Delphi Panel of Experts' Answers at a Glance Round 2.

\section{Discussion}

Considering the expressed opinions, it is noticed that there is an intricate organizational structure that, although it places the patient at the center of the system, frequently moves him to more peripheral positions due to the abundance of concurrent processes and subprocesses that are not always intertwined and can lead to additional connecting subprocesses, which generate delays in key intervals for diagnosis and treatment.

This lack of integration/reconfiguration mediated by the low adherence to organizational factors related to Dialogic Practices ${ }^{6}$ and relational Coordination ${ }^{7}$ motivates recurrence in inefficient interlevel processes that causes losses of value ${ }^{10}$ in the assistance and in the knowledge transmission cycle. ${ }^{11,12}$ It is to this respect when logic elements of reengineering have to be implemented to rationalize the steps the patient has to follow in his inter-level navigation. From this perspective and analyzing the contributions made by collaborators, the healthcare model should be redirected towards an integrating and reconfigured model that takes a competitive advantage of its available resources, know-how, demand, monopolistic power etc., which is granted by its status as a public health system.

On the other hand, system reconfiguration towards a shared vision that provides mechanisms and tools (protocols, clinical guidelines, etc.) which allows a smooth continuity of care, generation of synergies between levels, elimination of inefficiencies, optimization of resource allocation and results attributable to the organizational structure, finds its equivalence from the perspective of strategic management represented by Dynamic Capabilities, in clinical management approaches like the Triple AIM. ${ }^{13}$ This approach (Triple AIM) develops its theoretical framework on the basis of improving healthcare systems performance.

This theoretical convergence makes it possible to attribute a strategic character to this reconfiguration, which should be approached from the higher levels of the system in order to lead an effective transformation considering the mentioned management strategies, and even adopting a more focused position in sustainability strategies such as those that result of the application of Lean Management. ${ }^{14}$ This model of application in the business area, seeks to achieve superior performance for customers, workers, shareholders and society in general that applied to the healthcare field would translate into an increase in the added value of healthcare for patients, professionals, stakeholders and, of course, for society as a whole. The underlying philosophy based on the elimination of errors and unnecessary delays is fully applicable in the healthcare sector ${ }^{15}$ for the treatment of complex and multidisciplinary pathologies, since it ignores those steps that do not add value and, on the contrary, generate inefficiencies with negative consequences in health outcomes. The division between levels of care produces a deceleration in the flow of health care processes value creating artificial disconnections in the continuum of care. ${ }^{16}$ The application of joint clinical management strategies would contribute to enable decisions for patients' referral to specific resources at the right time ${ }^{17}$ thus eliminating intermediate steps and overproduction, generating, this way, a surplus of capacity to absorb the increase in demand due to the incidence and prevalence of the illness. ${ }^{1}$

These considerations suggest a reflection on the pertinence of the structural design of care provision. Health organizations must be considered as producers of an extraordinarily differentiated and valued service, which, however, cannot elude the convenience of managing their capacities and competencies. Beyond the value they bring in absolute terms, it is necessary for them to consider how to increase produced value and health gain by eliminating inefficiencies, flattening inter-level navigation and aligning its objectives throughout the different levels.

\section{Conclusion}

Throughout the study, a high variability has been observed in relation to the percentage of consensus obtained for each one of the raised items. This indicates that the organizational factors related 
to Relational Coordination and Dialogical Practices models have a medium degree of implementation and for some issues this degree turns to a low one. All of this leads to a reflection about the need to reconfigure current care processes to accommodate them to a real continuity of care and to a managed efficiency.

The case of lung cancer proposed for this paper is paradigmatic for assessing the different interrelationships between the organizational structures of both levels and analyzing its alignment as it is a complex pathology that requires an intense multidisciplinary approach and whose results, in terms of possibilities for increased survival, are linked to shortened temporal sequences for symptom-diagnosis, diagnosis-treatment and treatment-treatment intervals.

Likewise, the different perspectives (patient, professional, organizational and economic) that would be implemented as a consequence of joint strategies adoption have been evidenced along the paper. Notwithstanding the above, limitations are assumed in the study coming from the design of the questionnaire itself and questions formulation. These limitations could be countered in further investigations through questionnaire validation.

\section{Acknowledgements}

None.

\section{Conflict of interest}

The authors declare no conflict of interest.

\section{Funding}

This research has been funded with support from the Optimization and Energy Efficiency in the Management of the Cold Chain in Hospitals and Health Institutions Project.

\section{References}

1. Torre LA, Siegel RL, Jemal A. Lung cancer statistics. Adv Exp Med Biol. 2016;893:1-19.

2. Luengo R, Leal J, Gray A, et al. Economic burden of cancer across the European Union: a population-based cost analysis. Lancet Oncol. 2013;14(12):1165-1174.

3. Patel MI, Moore D, Blayney DW, et al. Transforming cancer care: are transdisciplinary approaches using design-thinking, engineering, and business methodologies needed to improve value in cancer care delivery? J Oncol Pract. 2014;10(2):e51-e54.
4. Romero JAV, Señarís JDL, Heredero CDP, et al. Relational coordination and healthcare management in lung cancer. World J Clin Cases. 2014;2(12):757-768.

5. Siegel RL, Miller KD, Jemal A. Cancer statistics. Ca Cancer J Clin. 2015;65:5-29.

6. Faraj S, Xiao Y. Coordination in fast-response organizations. Manage Sci. 2006;52:1155-1169.

7. Gittell JH. Relational coordination: guidelines for theory, measurement and analysis; 2017.

8. Camps C, Albanell J, Antón A, et al. Quality indicators to assure and improve cancer care in Spain using the delphi technique. J Natl Compr Canc Netw. 2016;14(5):553-558.

9. Valentine MA, Nembhard IM, Edmondson AC. Measuring teamwork in health care settings:a review of survey instruments. Med Care. 2015;53(4):e16-e30.

10. Chandra A, Staiger D. Sources of inefficiency in healthcare and education. Am Econ Rev. 2016;106(5):383-387.

11. Pisano GP. Knowledge, integration and the locus of learning:an empirical analysis of process development. Strat Mgmt J. 1994;15:85-100.

12. Dyer JH, Hatch NW. Relation-specific capabilities and barriers to knowledge transfers: creating advantage through network relationships. Strat Mgmt J. 2006;27(8):701-719.

13. Berwick DM, Nolan TW, Whittington J. The triple aim: care, health, and cost. Health Aff. 2008;27:759-769.

14. Simons P, Backes H, Bergs J, et al. The effects of a lean transition on process times, patients and employees. Int J Health Care Qual Assur. 2017;30(2):103-118.

15. Aguilar-Escobar VG, Garrido-Vega P. Lean logistics management in healthcare:a case study. Rev Calid Asist. 2013;28(1):42-49.

16. Kripalani S, LeFevre F, Phillips CO, et al. Deficits in communication and information transfer between hospital-based and primary care physicians:implications for patient safety and continuity of care. JAMA. 2007;297(8):831-841.

17. Grimshaw JM, Winkens RA, Shirran L, et al. Interventions to improve outpatient referrals from primary care to secondary care. Cochrane Database Syst Rev. 2005;3:CD005471. 